\title{
Airborne measurements of aerosol scattering properties above the MABL over Bay of Bengal during W ICARB - characteristics and spatial gradients
}

\author{
V. Sreekanth ${ }^{1}$, K. Krishna Moorthy ${ }^{1}$, S. K. Satheesh ${ }^{2,3}$, S. Suresh Babu ${ }^{1}$, Vijayakumar S. Nair ${ }^{1}$, and K. Niranjan \\ ${ }^{1}$ Space Physics Laboratory, Vikram Sarabhai Space Centre, Trivandrum - 695 022, India \\ ${ }^{2}$ Centre for Atmospheric and Oceanic Sciences, Indian Institute of Science, Bangalore - 560 012, India \\ ${ }^{3}$ Divecha Centre for Climate Change, Indian Institute of Science, Bangalore - 560 012, India \\ ${ }^{4}$ Department of Physics, Andhra University, Visakhapatnam - 530 003, India
}

Received: 13 June 2010 - Revised: 22 April 2011 - Accepted: 28 April 2011 - Published: 24 May 2011

\begin{abstract}
Realizing the importance of aerosol characterization and addressing its spatio-temporal heterogeneities over Bay of Bengal (BoB), campaign mode observations of aerosol parameters were carried out using simultaneous cruise, aircraft and land-based measurements during the Winter Integrated Campaign for Aerosols gases and Radiation Budget (W_ICARB). Under this, airborne measurements of total and hemispheric backscatter coefficients were made over several regions of coastal India and eastern BoB using a three wavelength integrating nephelometer. The measurements include high resolution multi-level (ML) sorties for altitude profiles and bi-level (BL) sorties for spatial gradients within and above the Marine Atmospheric Boundary Layer (MABL) over BoB. The vertical profiles of the scattering coefficients are investigated in light of the information on the vertical structure of the atmospheric stability, which was derived from the collocated GPS (Global Positioning System) aided radiosonde ascents. In general, the altitude profiles revealed that the scattering coefficient remained steady in the convectively well-mixed regions and dropped off above the MABL. This decrease was quite rapid off the Indian mainland, while it was more gradual in the eastern BoB. Investigation on horizontal gradients revealed that the scattering coefficients over northern $\mathrm{BoB}$ are 3 to 4 times higher compared to that of central BoB within and above the MABL. A north-south gradient in scattering coefficients is observed over Port Blair in the eastern BoB, with values decreasing from south to north, which is attributed to the similar gradient in the surface wind speed, which can be replicated in the
\end{abstract}

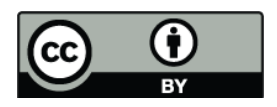

Correspondence to: S. Suresh Babu (s_sureshbabu@vssc.gov.in) sea salt abundance. The gradients are parameterized using best-fit analytical functions.

Keywords. Atmospheric composition and structure (Aerosols and particles)

\section{Introduction}

Marine aerosols play a key role in a number of climate processes. In addition to the direct and indirect effects (Haywood and Boucher, 2000) on the in-coming solar radiation, marine aerosols are also known to significantly affect the chemistry of atmosphere through heterogeneous and multiphase processes (von Glasow et al., 2002). They also act as cloud condensation nuclei thereby modifying the cloud microphysics such as droplet concentration and optical properties of marine stratocumulus, thereby influencing the precipitation rate and cloud lifetime (Twomey, 1977). Marine aerosol constitutes $30-35 \%$ of global aerosol abundance (Chin et al., 2002) of which sea-salt is the major contributor. Historically, the wealth of experimental data on the marine/oceanic aerosols is scarce when compared to that of continental aerosols due to (i) complexities in the measurements, and (ii) difficulties in the data collection. Concerted efforts like campaign mode cruise and/or airborne measurements are the chief sources of such information except a few island based long-term measurements (e.g. Moorthy and Satheesh, 2000; Smirnov et al., 2002; Moorthy and Babu, 2006). Nevertheless, several of these studies have shown significant heterogeneity in aerosol properties within the marine atmospheric boundary layer (MABL) as well as in vertical column in spatial and temporal scales, even over small oceanic regions (Bigg et al., 1995; Smirnov et al., 2002,

Published by Copernicus Publications on behalf of the European Geosciences Union. 


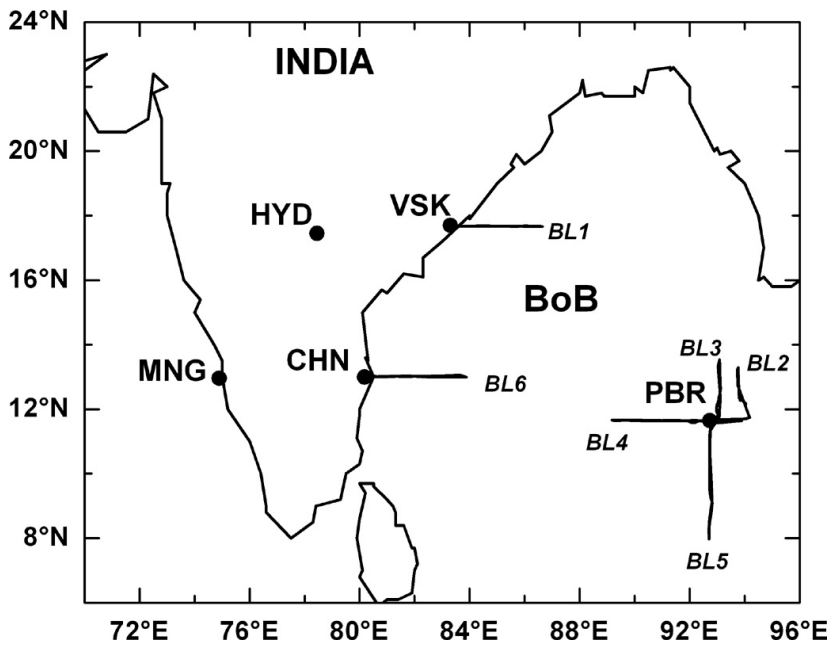

Fig. 1. Ground projection of the aircraft flight track during BL sorties along with the base stations overlaid on the Indian subcontinent map. Solid dots represent the geographical location of the base stations.

2003; Sakerin and Kabanov, 2002; Nair et al., 2008a; Moorthy et al., 2008).

Viewed in the backdrop of this, Bay of Bengal (BoB) attains importance in the south Asian region because of its association with Indian monsoon system and its proximity to densely populated landmasses. The recent, exhaustive field campaign, Integrated Campaign for Aerosols, gases and Radiation Budget (ICARB) (Moorthy et al., 2008) was the first major experiment that examined the entire $\mathrm{BoB}$ using cruise based, as well as island based measurements supplemented with airborne measurements from the east and west coasts of India (Moorthy et al., 2008; Babu et al., 2008; Nair et al., 2008a; Ramachandran and Rajesh, 2008; Satheesh et al., 2008, 2009). These measurements provided the first experimental observation of the prevalence of elevated aerosols over the Indian landmass and coastal waters during premonsoon season, occurring in the altitude region of 2 to $4 \mathrm{~km}$ within which the concentration and extinction were larger than those observed close to the surface and within the MABL (Babu et al., 2008; Satheesh et al., 2009). Nevertheless, the airborne measurements during ICARB-2006 were quite limited in their spatial coverage to coastal and western parts of the BoB and did not explore the central and far-off locations over the BoB. With a view to bridging this gap and also to examine the seasonal distinctiveness in the aerosol characteristics another integrated campaign (W_ICARB, W standing for Winter) was carried out during the winter season (December 2008-January 2009). During this experiment, extensive airborne measurements were made from the island station Port Blair (PBR, $\left.11.63^{\circ} \mathrm{N} ; 92.71^{\circ} \mathrm{E}\right)$ in the $\mathrm{BoB}$, in addition to the measurements from the coastal stations Visakhapatnam (VSK, $17.7^{\circ} \mathrm{N} ; 83.3^{\circ} \mathrm{E}$ ) and Chennai $\left(\mathrm{CHN}, 13^{\circ} \mathrm{N} ; 80^{\circ} \mathrm{E}\right)$ along the east coast of India, enabling a long longitudinal and latitudinal coverage. The data from these are examined to understand the vertical distribution of the aerosol scattering properties and its horizontal (spatial) variation within and above the MABL of BoB and the details are presented in this paper.

\section{Airborne measurements and database}

Airborne measurements were carried out onboard an instrumented propeller aircraft (Beechcraft 200), extensively across the east coast of India and over the BoB during the winter campaign W_ICARB, which was designed and carried out quite similar to ICARB in 2006 (Moorthy et al., 2008, for details). However, the period of the campaign was the winter season of 2008-2009 (from 27 December 2008-31 January 2009 ) and the focus was on the BoB and its far eastern parts.

During this campaign, a total of 17 sorties were carried out from five base stations as shown in Fig. 1 using the survey aircraft of National Remote Sensing Centre (NRSC). Of these, three were coastal locations viz., Visakhapatnam (VSK) and Chennai (CHN) on the east, Mangalore (MNG, located on the west coast of India); one from the island location Port Blair (PBR) in the BoB, besides the first base at the urban continental station Hyderabad (HYD). The coordinates of these locations and their physical characteristics are given in Table 1. VSK is an industrialized urban centre, with a major harbor, ship building unit, steel plant, and thermal power plant. Earlier studies have shown high AOD over this region. This region is also influenced by the long-range transport of effluents from the IGP through the low-level winds, which take them to the $\mathrm{BoB}$, where they are turned towards the southern coastal regions by the prevailing anti-cyclone (Niranjan et al., 2006). Chennai is a still larger urban centre, but with comparatively less industries, more of automobiles and other pollution sources and is influenced by the longrange transport from $\mathrm{BoB}$, (eastern $\mathrm{BoB}$ ) during this season (Moorthy et al., 2010). It is also a major harbor. Port Blair, is the admin cap of Andaman and Nicobar chain of islands, about $1300 \mathrm{~km}$ due east of VSK and Chennai. It is a fairly inhabited island with a population of about 0.36 million and the activities associated with it. It has a harbor and an airport, and a fairly good number of automobiles. However, there are no industries and the south of PBR are the Nicobar islands with dense tropical forests and the land area of the island chain is small compared to the surrounding oceanic area. It is known to be significantly influenced by long range transport from India as well as East Asia, during this season and its aerosol properties are known to show distinct responses to the change in advection (Moorthy and Babu, 2006). In general the boundary layer dynamics are subdued over PBR, compared to the other two mainland stations.

Each of the stations had a set of multi-level sorties (ML); bi-level sorties (BL) and single level (SL) sortie. While the ML sorties made high resolution vertical profiling of aerosol 
Table 1. Geographical coordinates and characteristics of the base stations.

\begin{tabular}{ccclccc}
\hline \multirow{2}{*}{ Location } & Lat $\left({ }^{\circ} \mathrm{N}\right)$ & Long $\left({ }^{\circ} \mathrm{E}\right)$ & Nature of the location & \multicolumn{2}{c}{ Number of sorties } \\
\cline { 4 - 6 } & & & ML & BL & SL \\
\hline HYD & 17.45 & 78.45 & Inland, urban and industrialized & 1 & 0 & 1 \\
VSK & 17.7 & 83.3 & Coastal, urban and industrialized & 1 & 1 & 0 \\
PBR & 11.63 & 92.71 & Island & 1 & 4 & 0 \\
CHN & 13 & 80 & Coastal, urban and industrialized & 0 & 1 & 1 \\
MNG & 12.96 & 74.89 & Coastal and urban & 1 & 0 & 1 \\
\hline
\end{tabular}

Table 2. Details of the ML and BL sorties and their spatial coverage.

\begin{tabular}{|c|c|c|c|c|}
\hline Sortie name & Originating base station & Date & Period/duration (LT) & Lat./Long. Coverage $\left({ }^{\circ}\right)$ \\
\hline ML1 & VSK & 4 Jan 2009 & 09:30-13:30 4h & $17.7^{\circ} \mathrm{N}, 83.8-85.5^{\circ} \mathrm{E}$ \\
\hline ML2 & PBR & 12 Jan 2009 & 06:30-09:30 $3 \mathrm{~h}$ & $11.65^{\circ} \mathrm{N}, 92.85-94.25^{\circ} \mathrm{E}$ \\
\hline BL1 & VSK & 5 Jan 2009 & $09: 30-12: 303 \mathrm{~h}$ & $17.7^{\circ} \mathrm{N}, 83.4-86.7^{\circ} \mathrm{E}$ \\
\hline BL2 & PBR & 9 Jan 2009 & $06: 30-09: 303 \mathrm{~h}$ & $11.5-13.3^{\circ} \mathrm{N} 92.7-94.2^{\circ} \mathrm{E}$ \\
\hline BL3 & PBR & 9 Jan 2009 & $10: 30-13: 002.5 \mathrm{~h}$ & $11.5-13.7^{\circ} \mathrm{N} 93^{\circ} \mathrm{E}$ \\
\hline BL4 & PBR & 13 Jan 2009 & 06:00-09:00 3h & $11.65^{\circ} \mathrm{N} 89-92.8^{\circ} \mathrm{E}$ \\
\hline BL5 & PBR & 14 Jan 2009 & $06: 00-09: 303.5 \mathrm{~h}$ & $8-11.8^{\circ} \mathrm{N} 92.7^{\circ} \mathrm{E}$ \\
\hline BL6 & $\mathrm{CHN}$ & 16 Jan 2009 & 10:00-13:00 3h & $13^{\circ} \mathrm{N} 80-84.4^{\circ} \mathrm{E}$ \\
\hline
\end{tabular}

parameters up to $\sim 3000 \mathrm{~m}$ altitude (at $\sim 500,1000,1500$, $2000,2500,3000 \mathrm{~m}$ a.g.1.) over the survey location and had short spatial coverage of $\leq 150 \mathrm{~km}$ at each level, the BL sorties comprised of two measurements one within the Atmospheric Boundary Layer (ABL) ( 700 m a.g.1.) and the other well above $(\sim 1500 \mathrm{~m}$ a.g.l.) and covered long horizontal distances of $\sim 400 \mathrm{~km}$ at each level so as to provide information on the spatial gradients within the ABL and above. The single level sorties were made always well above the ABL ( $~ 1500 \mathrm{~m}$ to $2500 \mathrm{~m}$ a.g.1.), while the aircraft ferried from one base to the other. Its altitude varied depending on the flight requirements and orography of the underlying land area (such as presence of hills or mountains and as such have very limited use in understanding gradients). The horizontal lines in Fig. 1 show the ground projection of the aircraft flight path during the BL sorties, while Fig. 2 show typical examples of ML and BL sorties. The number of sorties of each category from the bases is also given in the last of column of Table 1. The details of the ML and BL sorties including date, time, originating station, longitude/latitudinal coverage are also given in Table 2.

During each sortie, measurements were carried, ambient air being sampled by the onboard instruments through a set of inlets fitted under the belly of the aircraft, close to its nose, such that the inlet opens into the incoming air as the aircraft flew (Moorthy et al., 2004; Babu et al., 2008). A highly sensitive GPS receiver (Trimble) was employed to obtain the information on its position, altitude, as well as time during the sorties at every one-second interval. The scattering coefficients were measured using a three color integrating Nephelometer (model 3563 of TSI Inc., USA), operated continuously during the flight. It yielded the aerosol total scattering coefficient $\left(\sigma_{\mathrm{tsc}}\right)$ and hemispheric backscatter coefficient $\left(\sigma_{\text {bsc }}\right)$ at 450,550 and $700 \mathrm{~nm}$. The aircraft was kept unpressurised during these sorties and as such the maximum altitude for the sorties was limited to $\sim 3 \mathrm{~km}$. In all, $2 \mathrm{ML}$ (one each over VSK and PBR) and 6 BL (one off-VSK, one off$\mathrm{CHN}$ and 4 off-PBR) sorties were made over the BoB and these data are examined for the spatial variation of aerosol scattering properties. Off these BL1 (from VSK), BL4 (from PBR) and BL6 (from CHN) were to study the longitudinal variation and BL3 and BL5 (both from PBR) were to study the latitudinal variation.

\section{Data analysis and derived parameters}

The Nephelometer provided continuous information on the coefficients of total scattering $\sigma_{\text {tsc }}$ and hemispheric backscatter $\sigma_{\text {bsc }}$ at its three operating wavelengths $450,550,700 \mathrm{~nm}$ during each measurement at $1 \mathrm{~min}$ interval. Here it is worth mentioning that data collected during the ascent or descent of the aircraft has been removed from the database and not utilized in the analysis. The principle of Nephelometry, details of the data analysis, and correction for angular truncation errors are described by Anderson et al. (1996) and Anderson and Ogren (1998) and its application to the ICARB data by 

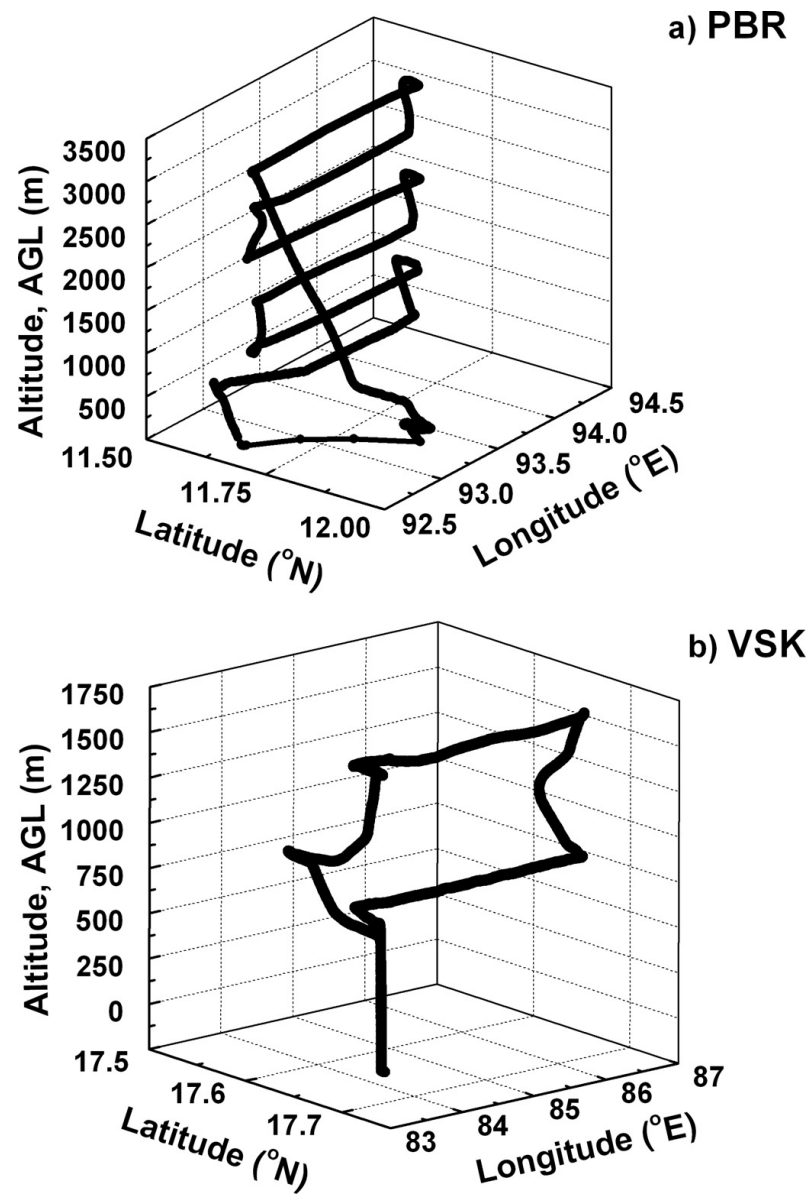

Fig. 2. Typical example of an ML and BL sortie. (a) circuit of the aircraft track during ML sortie over PBR, (b) circuit of the aircraft track during BL sortie off-VSK.

Nair et al. (2009). The instrument was calibrated before the campaign using $\mathrm{CO}_{2}$ as high span gas and clean aerosol free air as low span gas following Anderson et al. (1996). The inherent angular truncation error, arising out of the inability of the nephelometer to measure at angles above $170^{\circ}$ and below $7^{\circ}$, leads to a reduction in the measured scattering coefficient especially for super-micrometer particles. This was corrected using the spectral information of scattering coefficients, as described by Anderson and Ogren (1998). In general, the uncertainties in the derived scattering coefficients were nearly $10 \%$.

As the aerosol scattering characteristics strongly depend on the relative humidity values at which they are measured, the ambient scattering coefficients are corrected for $60 \%$ relative humidity (RH) following Hanel (1976). Firstly, the ambient scattering coefficients are brought to zero RH (dry) state using the scale factors for the "decreasing humidity curve" of marine model of Hanel (1976). Then the values are brought to $60 \% \mathrm{RH}$ using the scale factors for the "increasing humidity curve".
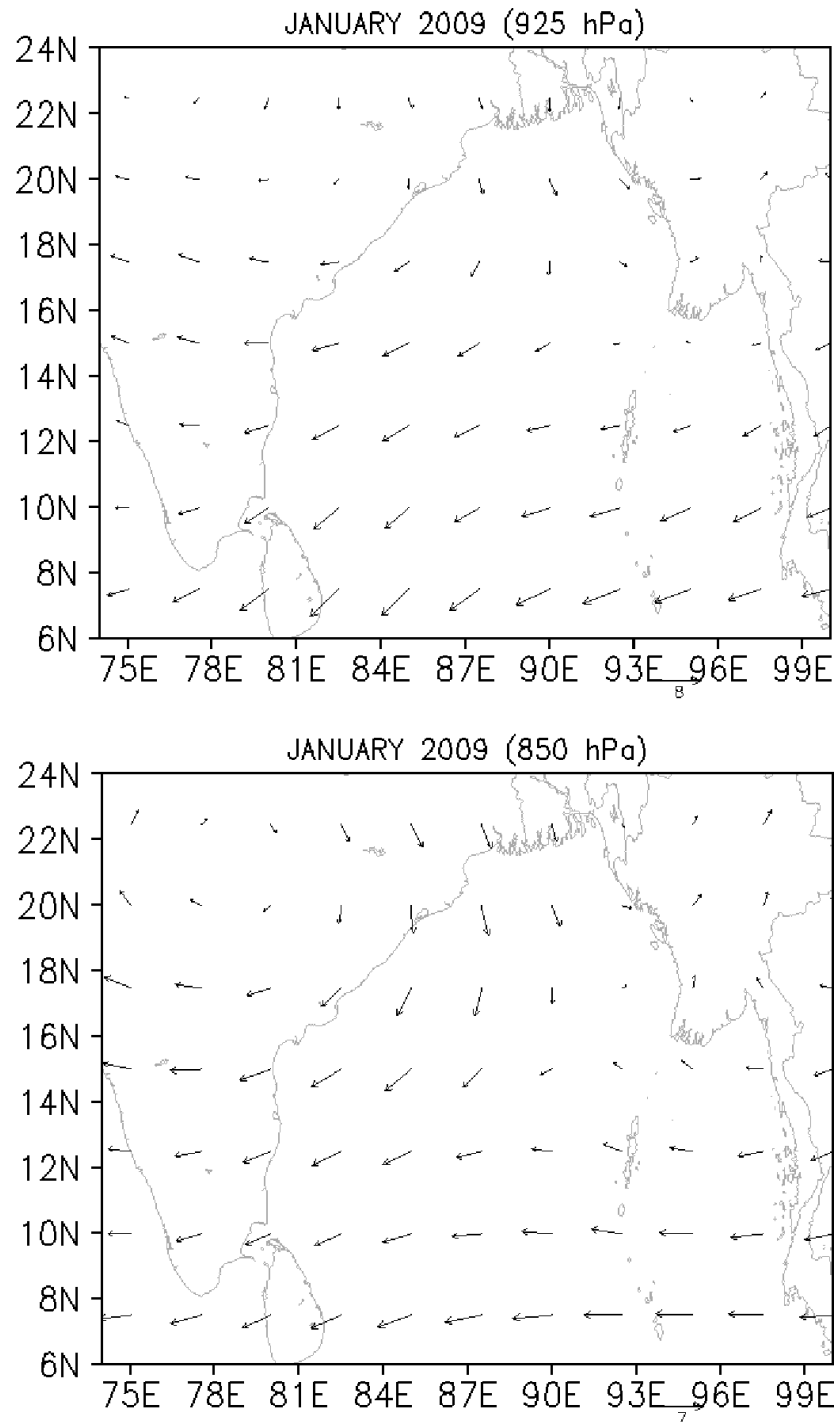

Fig. 3. NCEP/NCAR derived monthly mean (January 2009) wind patterns at pressure levels 925 (upper panel) and $850 \mathrm{hPa}$ (lower panel), corresponding to $\sim 770$ and $1550 \mathrm{~m}$ altitudes above ground level (a.g.1.).

The corrected spectral $\sigma_{\text {tsc }}$ and $\sigma_{\text {bsc }}$ values are used to compute the wavelength exponent, $\alpha$, and hemispheric backscatter ratio $b$. The wavelength exponent $\alpha$ of $\sigma_{\text {tsc }}$ is the parameterization of the spectral dependence of the scattering coefficient by approximating $\sigma_{\text {tsc }}$ variation with wavelength to the Ångström relation (Ångström, 1964). Accordingly,

$\sigma_{\mathrm{tsc}}(\lambda)=\beta \lambda^{-\alpha}$

It depends strongly on the aerosol size distribution and refractive index. Higher values of $\alpha(>1)$ indicate dominance of accumulation mode aerosols in the size distribution.

The hemispheric backscatter ratio is defined as the ratio of light scattered into the backward hemisphere $\left(\sigma_{\mathrm{bsc}}\right)$ to total scattering $\left(\sigma_{\text {tsc }}\right)$ and as such 

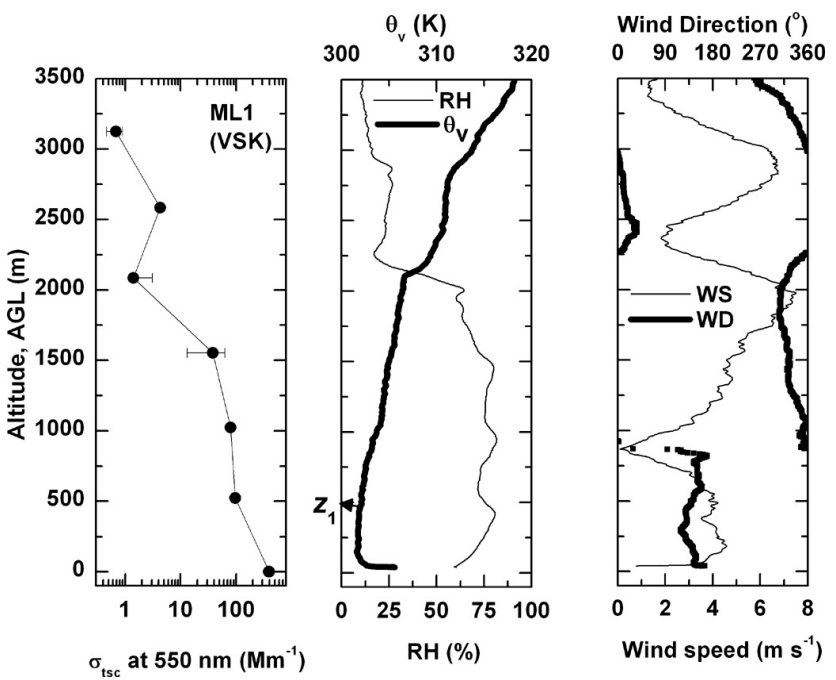

Fig. 4. Vertical profiles of $\sigma_{\text {tsc }}$ (left panel); virtual potential temperature $\left(\theta_{\mathrm{v}}\right.$, thick solid line in the middle panel), relative humidity (RH, thin solid line in the middle panel); wind direction (WD, thick solid line in the right panel), wind speed (WS, thin solid line in the right panel) over VSK during ML1. $z_{1}$ denotes the vertical extent of the well-mixed region.

$b_{\lambda}=\frac{\sigma_{\mathrm{bsc}}(\lambda)}{\sigma_{\mathrm{tsc}}(\lambda)}$

\section{Prevailing meteorology}

The prevailing meteorology during the campaign period comprised mainly calm synoptic conditions with moderate winds and clear or partially cloudy skies. The monthly mean picture of the prevailing synoptic winds at $850 \mathrm{hPa}$ and $925 \mathrm{hPa}$ over Bay of Bengal for the month of January 2009 is shown in Fig. 3 (derived from NCEP/NCAR reanalysis data). These pressure levels corresponds to the altitude levels of $\sim 1550 \mathrm{~m}$ and $\sim 770 \mathrm{~m}$ altitudes above ground level where the first and seconds levels of boundary layer (BL) sorties were made. The synoptic wind pattern revealed the prevalence of a continental airmass over the entire BoB during the campaign period, originated from distinct geographical regions.

\section{Results and discussion}

\subsection{Altitude profiles}

The ML sorties off VSK and PBR were made across the longitudes (eastwards) from the base stations into the oceanic atmosphere over BoB. As such, the profile off-VSK is representative of the environment over coastal waters adjoining the eastern landmass of India and that off-PBR represents the far eastern scenario, mostly under the influence of east Asia, in view of prevailing easterly/north easterly nature of the winds. Figures 4 and 5 show the profiles of $\sigma_{\text {tsc }}$ at
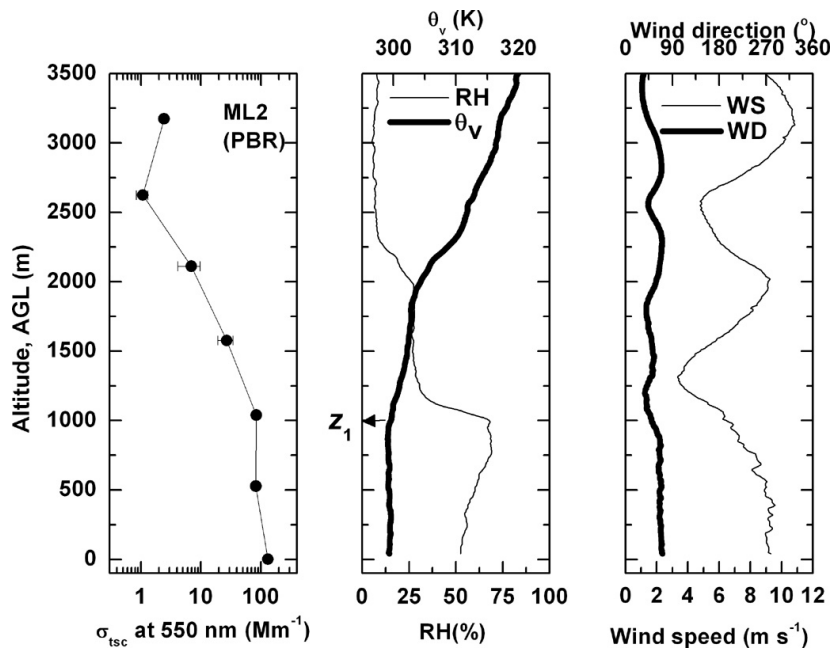

Fig. 5. Same as Fig. 3 but over PBR during ML2.

$550 \mathrm{~nm}$ off-VSK (left panel of Fig. 4) and off-PBR (left panel of Fig. 5) during ML1 and ML2 sorties respectively. In the right panels are shown the vertical profiles of meteorological parameters obtained from GPS aided radio-sonde measurements (Alappattu et al., 2008) made from the respective base stations on the same days of the sorties, but shifted in time by a couple of hours due to technical requirement. During ML1 on 4 January 2009, the scattering coefficient near the surface off-VSK was as high as $395 \mathrm{M} \mathrm{m}^{-1}$ representing the highly aerosol laden environment over VSK, which is a coastal, urban and industrialized port city having an industrial belt comprising of steel factory, fertilizer, polymer, zinc industry, oil refinery and the India's largest shipbuilding yard. As the altitude increased, $\sigma_{\text {tsc }}$ gradually decreased to $\sim 40 \mathrm{M} \mathrm{m}^{-1}$ at an altitude of $1500 \mathrm{~m}$. Above this $\sigma_{\text {tsc }}$ decreased dramatically, dropping off to $\sim 1 \mathrm{M} \mathrm{m}^{-1}$ at $2 \mathrm{~km}$ and above. In this context, we examined the vertical profiles of meteorological parameters obtained from the GPS-sonde ascents. These included profiles of wind parameters (speed $\left(\mathrm{m} \mathrm{s}^{-1}\right)$ and direction $\left.\left({ }^{\circ}\right)\right)$, Temperature $\left({ }^{\circ} \mathrm{C}\right)$ and Relative humidity $(\mathrm{RH}$ $\%$ ) at $\sim 5 \mathrm{~m}$ interval. From these, the vertical profiles of specific humidity and virtual potential temperature $\left(\theta_{\mathrm{v}}\right)$ (Stull, 1988) were estimated. The altitude variation of these parameters for the lower atmospheric region up to $3.5 \mathrm{~km}$ (the ceiling altitude of the aircraft sorties) is shown in the middle and right panels of Fig. 4 (off-VSK) and 4 (off-PBR), by the side of the vertical profiles of $\sigma_{\text {tsc }}$. In the Figs. 4 and 5 the thick solid lines in the middle panel correspond to virtual potential temperature $\left(\theta_{\mathrm{v}}\right)$ while the thick solid lines in the right panel correspond to the wind direction. The thin solid lines in the middle and right panels refer to relative humidity and wind speeds, respectively. At VSK, the $\theta_{\mathrm{v}}$ remained nearly steady with altitude up to $\sim 425 \mathrm{~m} \mathrm{(} z_{1}$ in panel two of Fig. 4) indicating the vertical extent of the well-mixed region. Above that, $\theta_{\mathrm{v}}$ increased with altitude very gradually 
up to an altitude of $\sim 2000 \mathrm{~m}$ representing a near-neutral and convectively less unstable region, with slight sub-adiabatic lapse rate. At $\sim 2000 \mathrm{~m}$, a sharp inversion in $\theta_{\mathrm{v}}$ is seen, with convectively stable sub-adiabatic conditions above. Another convectively unstable, thin layer is noticed in the region of 2500-2800 m, at the top of which $\theta_{\mathrm{v}}$ again shows an inversion; changing to stable conditions above. RH remained nearly steady with a mean value of $70 \%$ up to $2000 \mathrm{~m}$ altitude. Above that, RH sharply dropped off to $\sim 20 \%$ representing the prevalence of dry airmass. The wind speeds were in the range $1-8 \mathrm{~m} \mathrm{~s}^{-1}$, characterized by two peaks at $\sim 2000$ and $3000 \mathrm{~m}$ altitude. Easterlies (having long history over the ocean) prevailed up to $1000 \mathrm{~m}$ altitude and shifted to (continental) northerly/northwesterly at higher levels suggesting the presence of distinctly different dry airmass above the (M)ABL over VSK, extending to higher altitude regions.

Over PBR, during ML2 on 12 January 2009, the surface value of $\sigma_{\mathrm{tsc}}$ was $\sim 130 \mathrm{M} \mathrm{m}^{-1}$, nearly $66 \%$ lower than that seen off-VSK, indicating the comparatively cleaner environment over this island which is located in the far eastern $\mathrm{BoB}$. Nevertheless this value is considerably higher than the values reported over pristine oceans (Anderson et al., 1999), and also higher than the values $\left(\sim 25 \mathrm{M} \mathrm{m}^{-1}\right)$ observed over the southeastern BoB during ICARB-2006 (Nair et al., 2009). The concentration decreased, albeit very gradually with altitude, to reach $\sim 100 \mathrm{M} \mathrm{m}^{-1}$ at $1000 \mathrm{~m}$ level, showing a wellmixed vertical distribution of aerosols. Above this level, $\sigma_{\text {tsc }}$ dropped off rapidly (similar to the case off-VSK) to reach a value as low as $\sim 1 \mathrm{M} \mathrm{m}^{-1}$ at around $\sim 2500 \mathrm{~m}$ altitude, even though the vertical gradient over PBR $\left(\frac{\partial \sigma_{\text {tsc }}}{\partial z}=\sim\right.$ $55 \mathrm{M} \mathrm{m}^{-1} \mathrm{~km}^{-1}$ ) was shallower than that seen off-VSK in Fig. 4 (where $\frac{\partial \sigma_{\text {tsc }}}{\partial z}=\sim 80 \mathrm{M} \mathrm{m}^{-1} \mathrm{~km}^{-1}$ ). Vertical profiles of the data from the GPS ascents made on 11 January 2009 (onboard Oceanographic Research Vessel Sagar Kanya, which was sailing in the eastern $\mathrm{BoB}$, close to PBR, but on the eastern side $\left(10.78^{\circ} \mathrm{N}, 96.1^{\circ} \mathrm{E}\right)$ as a part of the ocean segment of W_ICARB), are examined in the middle and right panels of Fig. 5. Profile of $\theta_{\mathrm{V}}$ shows a well-evolved convective boundary layer extending upto $\sim 1000 \mathrm{~m}\left(z_{1}\right)$, within which the RH remained high and showed an increase from $\sim 50 \%$ at surface to $\sim 70 \%$ at $1000 \mathrm{~m}$. In this region $\sigma_{\text {tsc }}$ (at $550 \mathrm{~nm}$ ) remained nearly steady with a mean value of $100 \mathrm{M} \mathrm{m}^{-1}$. A very sharp and well defined inversion occurs in $\theta_{\mathrm{v}}$ at $1000 \mathrm{~m}$ (top of the convective MABL), above which $\theta_{\mathrm{v}}$ increased suggesting convectively stable condition upto $\sim 2000 \mathrm{~m}$. The RH rapidly dropped off to $20 \%$ just above the inversion (at $1000 \mathrm{~m}$ ) and remained nearly at the same level upto $2000 \mathrm{~m}$ and decreased further above implying the prevalence of dry synoptic winds. The aerosols in the wellmixed MABL being confined by the inversion at $1000 \mathrm{~m}$, the air above is rather clean resulting in a rapid fall in $\sigma_{\text {tsc }}$ values to near background levels by $\sim 2000 \mathrm{~m}$. The wind direction has been almost steady northeasterly throughout the altitude range in line with the synoptic conditions, while the wind speed varied considerably.The columnar AOD (Aerosol Optical Depth) derived from MODIS (Aqua) $1^{\circ} \times 1^{\circ}$ grid data for each of the days over the sortie region during ML1 and ML2 were 0.53 and 0.24 . The scattering AOD, estimated by integrating the ambient scattering coefficient, in the altitude region $0-3000 \mathrm{~m}$ was $\sim 0.22$ and 0.14 which accounted for nearly $45 \%$ and $60 \%$ to the columnar AOD off the coastal base Visakhapatnam (VSK, north-western BoB) and off the island base PBR (eastern BoB) respectively, suggesting most of the aerosol was confined to lower troposphere, particularly over PBR, during winter, in contrast to that of pre-monsoon season (Satheesh et al., 2006).

\subsection{Longitudinal variations}

The longitudinal variation of the total scattering coefficient $\left(\sigma_{\text {tsc }}\right)$ at $550 \mathrm{~nm}$ across the eastern coastline of Indian mainland is examined in Fig. 6 at two altitudes $770 \mathrm{~m}$ (within $\mathrm{ABL}$ ) and $1550 \mathrm{~m}$ (above $\mathrm{ABL}$ ) during the sortie BL1 that originated from VSK $\left(17.7^{\circ} \mathrm{N}\right)$ on 5 January 2009 . The vertical pointing arrow on the $\mathrm{X}$-axis shows the longitude of VSK airport, from where the aircraft flew eastward up to $\sim 87^{\circ}$ across longitudes over the northern BoB at $770 \mathrm{~m}$ altitude, then climbed to $1550 \mathrm{~m}$ and returned to the base, retracing the track. The variations of $\sigma_{\text {tsc }}$ in Fig. 6 shows that at the lower altitude, within the MABL, the scattering coefficient exhibited no clear trend throughout the longitude range, it rather remained high and fluctuated about a mean value of $\sim 227 \pm 13 \mathrm{M} \mathrm{m}^{-1}$. This mean value, though inline with those seen during the ML1 sortie, was much higher than the near surface values $\left(\sim 145 \pm 16 \mathrm{M} \mathrm{m}^{-1}\right)$ reported by Nair et al. (2008a) over this part of the BoB during pre-monsoon season of 2006. At the higher altitude $(1550 \mathrm{~m})$, however, $\sigma_{\text {tsc }}$ showed a more organized pattern, probably because of being far away from the source impacts; remaining nearly steady with a mean value of $\sim 150 \pm 6 \mathrm{M} \mathrm{m}^{-1}$ up to $85^{\circ} \mathrm{E}$ and decreasing rapidly there after to reach values as low as $65 \mathrm{M} \mathrm{m}^{-1}$ beyond $86^{\circ} \mathrm{E}$ longitude. This decrease beyond $85^{\circ} \mathrm{E}$ could be best parameterized using an exponential decay function of the form

$\sigma_{\mathrm{tsc}}(\lambda)=A+B \exp \left(-\phi / \phi_{\mathrm{D}}\right)$

with a correlation coefficient of 0.94 and a value of $0.34^{\circ}$ for the $\mathrm{e}^{-1}$ scaling distance $\phi_{\mathrm{D}} . A$ and $B$ are constants representing the offset and amplitude of the exponential fit. This analytical function, fitted to the measurements is shown by the continuous line in Fig. 6. The data gaps in the Fig. 6 are due to the periodical "zero-measurement" of the nephelometer in order to estimate the inherent background noise of the instrument. Examining the wind fields, we noticed that during BL1, at both the altitudes the winds were moderate northerlies, arriving from north/central India (Fig. 3) aided by the anti-cyclonic circulation there, which turned the westerlies/north-westerlies to northerlies. Through a forward trajectory analysis, Niranjan et al. (2006) have shown that the 


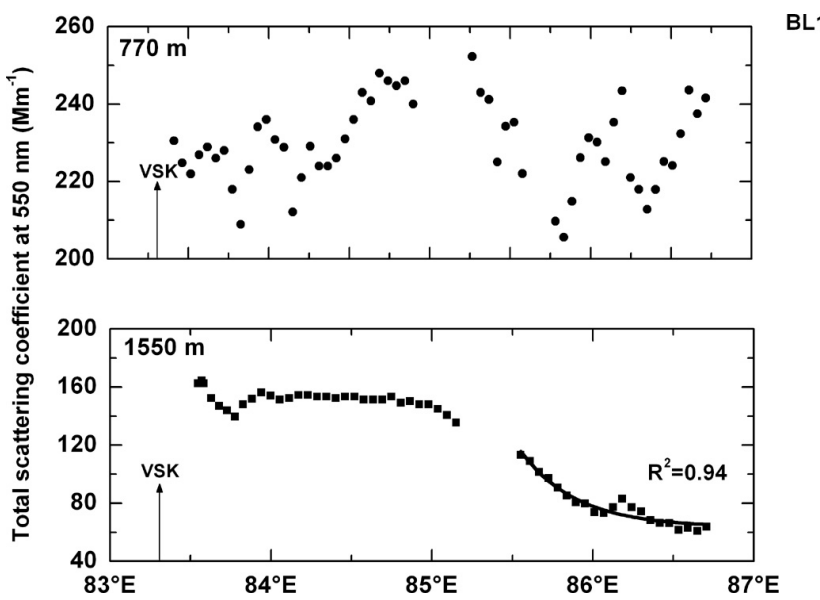

Fig. 6. Longitudinal variation of $\sigma_{\text {tsc }}$ at 770 (upper panel) and $1550 \mathrm{~m}$ (lower panel) altitude off-VSK during BL1 over $17.7^{\circ} \mathrm{N}$ latitude. Solid line indicates the best exponential decay function beyond $85^{\circ} \mathrm{E}$. The arrows in both the panels represent the longitude of VSK airport.

transport from the Indo-Gangetic plains have the potential to contribute to the aerosol loading over the northern BoB adjoining VSK, through long-range transport. With a view to examining this, seven day back trajectories were computed using the HYbrid Single Particle Lagrangian Integrated Trajectory (HYSPLIT) model of National Oceanic and Atmospheric Administration (NOAA; Draxler and Rolph, 2003) for six locations along the flight track, at 770 (full lines) and $1550 \mathrm{~m}$ (dashed lines) altitudes and are shown in Fig. 7. At both the altitudes, the trajectories arriving the study region originated from the Indo-Gangetic plains and central India, thereby confirming that the high aerosol load observed close to the coast was contributed by significant advection from the Indo-Gangetic plains, which is known to be a highly aerosol laden region during winter (Nair et al., 2007).

In the light of the above, we examined the longitudinal variation of $\sigma_{\text {tsc }}$ from CHN (BL6), a location $\sim 4^{\circ}$ down VSK (Fig. 1) which is considered to represent the central BoB. This sortie was carried out on 16 January 2009 and the results are shown in Fig. 8. The most obvious feature is the drastically reduced values of $\sigma_{\text {tsc }}$ off-CHN (central BoB) at both the altitudes. In sharp contrast to the values $>200 \mathrm{M} \mathrm{m}^{-1}$ and $\sim 150 \mathrm{M} \mathrm{m}^{-1}$, respectively, at $770 \mathrm{~m}$ and $1550 \mathrm{~m}$ altitudes off-VSK, at CHN the values were only between 30 and $80 \mathrm{M} \mathrm{m}^{-1}$ (nearly 5-fold decrease). The longitudinal variation also showed a contrast with $\sigma_{\text {tsc }}$ decreasing initially as we moved off the airport in the city, to reach values as low as $30 \mathrm{M} \mathrm{m}^{-1}$ at $\sim 81^{\circ} \mathrm{E}$ and subsequently increasing rapidly to reach $\sim 60 \mathrm{M} \mathrm{m}^{-1}$ at 770 and $\sim 40 \mathrm{M} \mathrm{m}^{-1}$ at $1550 \mathrm{~m}$. At both these levels $\sigma_{\text {tsc }}$ continued to increase, though gradually, into the open ocean indicating an eastward gradient at both the altitudes. The rate of the increase was $\sim 7 \mathrm{M} \mathrm{m}^{-1}$ per degree increase in longitude at $770 \mathrm{~m}$, while it was $\sim 2 \mathrm{M} \mathrm{m}^{-1}$

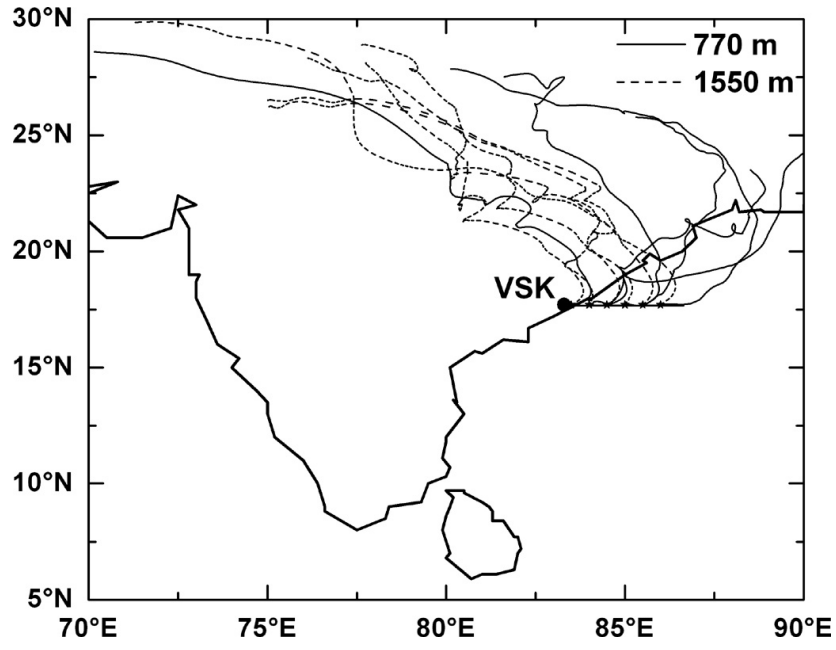

Fig. 7. Seven-day isentropic back trajectories at six locations in the flight track during BL1 at 770 (full lines) and $1550 \mathrm{~m}$ (dashed line) altitude a.g.l. Solid round dot represents the location of the base station.

at $1550 \mathrm{~m}$ altitude. These low values off-CHN, despite of it being a much larger urban center than VSK, were rather unexpected and not in-line with earlier measurements (Satheesh et al., 2009). Further, the eastward gradients, with $\sigma_{\text {tsc }}$ increasing eastward over the BoB, is in sharp contrast to the decreasing trend in the extinction coefficients, reported earlier by Satheesh et al. (2009) based on airborne Lidar measurements during the pre-monsoon (March-April) season of 2006. Examining the mean winds in Fig. 3, it emerges that the northerlies in the northern BoB (seen off-VSK) have changed to easterlies at both the levels off-CHN, arriving from open ocean. This would bring-in a much cleaner air than those arrived at VSK (from the Indo-Gangetic plains) and would be contributing to the low values of $\sigma_{\mathrm{tsc}}$. The eastward increasing trend in $\sigma_{\text {tsc }}$ is indicative of source regions of far-east (east Asian) continents. Significant impact of fine mode aerosols, advected from east Asia in enhancing the AOD, accumulation mode abundance and black carbon, over eastern BoB during winter have been also observed in earlier measurements from PBR (Moorthy et al., 2003; Moorthy and Babu, 2006). The present observations also corroborate these. Seven-day back trajectory analysis (for six locations in the flight track) in this case (Fig. 9) revealed that the airmass was, in-fact, arriving from the east Asian region, and has a fairly long history over the oceanic environment of BoB, thereby confirming the above. The decrease, shortly after the airport could be due to the modulation of the synoptically driven airmass by the region specific local effects of the city.

With these two contrasting patterns in the gradients from the mainland over to ocean in the backdrop, we now shift the focus to the longitudinal variation of $\sigma_{\text {tsc }}$ from the island station $\mathrm{PBR}\left(11.63^{\circ} \mathrm{N}, 92.71^{\circ} \mathrm{E}\right)$ in the eastern BoB 
BL6

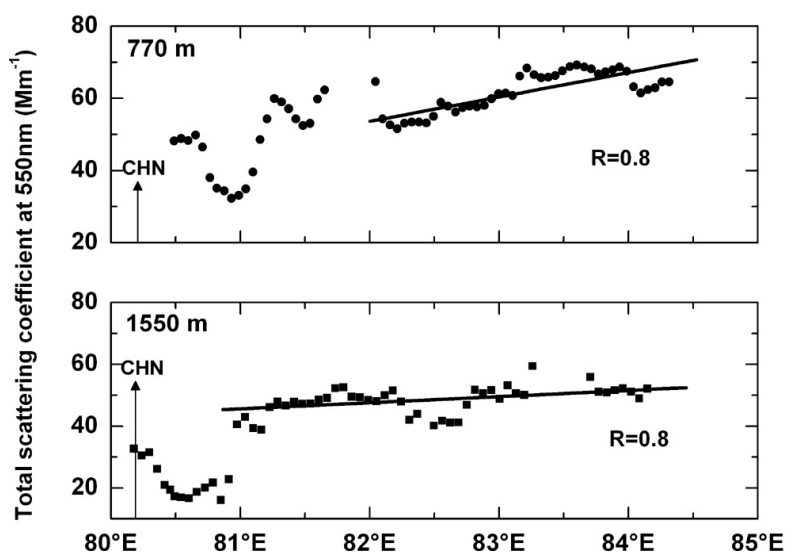

Fig. 8. Longitudinal variation of $\sigma_{\text {tsc }}$ at 770 (upper panel) and $1550 \mathrm{~m}$ (lower panel) altitude off-CHN during BL6 over $13^{\circ} \mathrm{N}$ latitude. Solid line represents best linear fit showing increasing trend in $\sigma_{\text {tsc }}$ values off-CHN into central BoB. The arrows in both the panels represent the longitude of $\mathrm{CHN}$ airport.

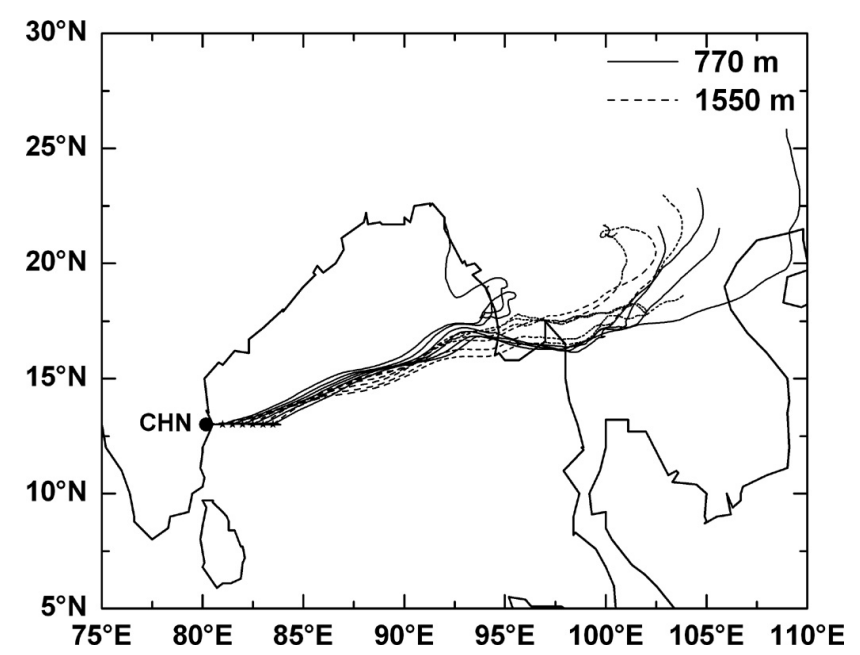

Fig. 9. Same as Fig. 7, but during BL6.

during BL4, when the aircraft flew westward from PBR into the eastern BoB. The results are shown in Fig. 10. At the lower altitude $(770 \mathrm{~m}), \sigma_{\text {tsc }}$ fluctuated about a mean value $\sim 80 \pm 5 \mathrm{M} \mathrm{m}^{-1}$ with a very weak increase near to PBR. This value, though is almost 3 times lesser compared to that during BL1, is interestingly, significantly higher than the mean value of $\sim 56 \pm 9 \mathrm{M} \mathrm{m}^{-1}$ seen off-CHN, and in general conformity to the eastward gradient seen off-CHN. The eastward increasing trend in $\sigma_{\text {tsc }}$ observed during BL6 (Fig. 8) is seen in this sortie also, though it is weaker, particularly at $1550 \mathrm{~m}$ level. The mean value of $\sigma_{\text {tsc }}$ at $1550 \mathrm{~m}$ was $\sim 43 \pm 13 \mathrm{M} \mathrm{m}^{-1}$. The seven day back trajectory analysis (Fig. 11) here shows that the airmass reaching over PBR at both the altitudes, were similar to those seen for BL6 (Fig. 9) except that, they have a longer continental over pass and

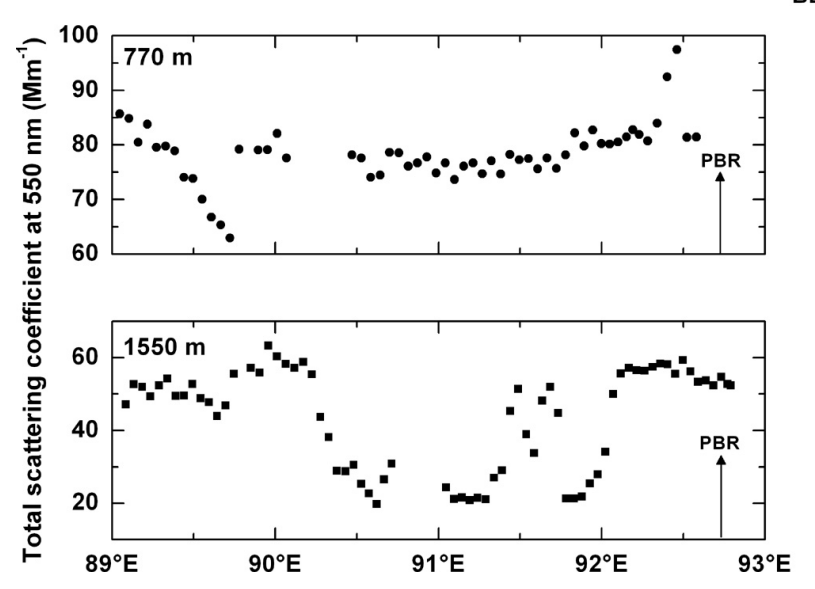

Fig. 10. Longitudinal variation of $\sigma_{\text {tsc }}$ at 770 (upper panel) and $1550 \mathrm{~m}$ (lower panel) altitude off-PBR during BL4 over $11.65^{\circ} \mathrm{N}$ latitude. The arrows in both the panels represent the longitude of PBR airport.

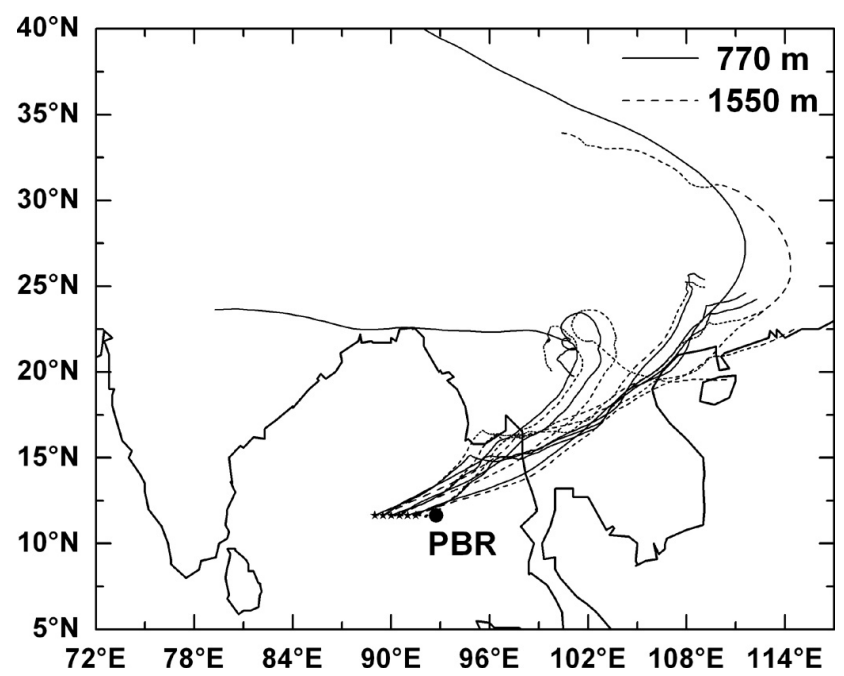

Fig. 11. Same as Fig. 7, but during BL4.

shorter history over the sea than when they reached CHN. These observations are in general conformity with eastward increasing trend reported by Nair et al. (2009) over northern BoB based on shipboard measurements of $\sigma_{\text {tsc }}$ using nephelometer during ICARB-2006, thereby vindicating the strong influence of east Asian source regions on central BoB, both within and above the MABL.

Both sorties, BL6 and BL4, representing the central BoB, experience winds mainly from the east of the $\mathrm{BoB}$ while, the BL1 sortie representing northern $\mathrm{BoB}$ experienced winds mostly from the north/central India at both the altitudes (Fig. 3). From a climatological analysis of wind fields Satheesh et al. (2006) have also reported that during winter, at $500 \mathrm{~m}$ level, about $68 \%(75 \%$ at $1500 \mathrm{~m}$ and $79 \%$ at $2500 \mathrm{~m}$ ) of the time airmasses influencing northern BoB 
BL6+BL4

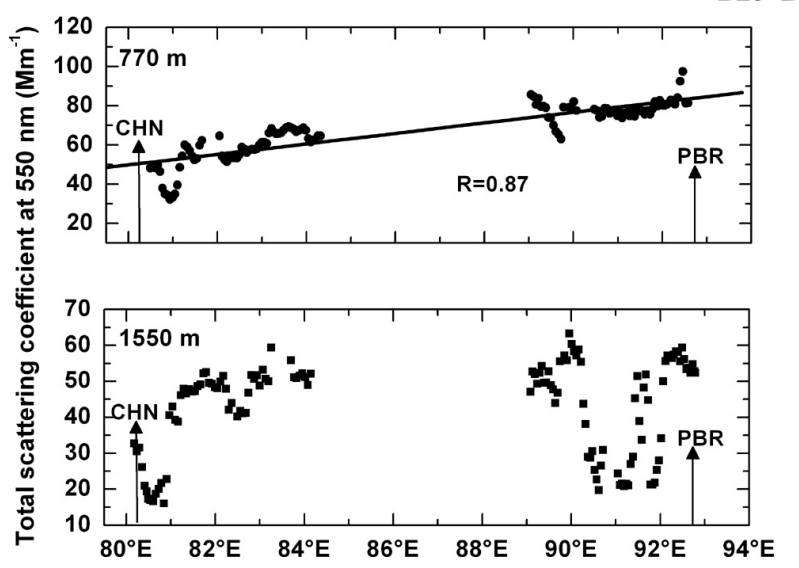

Fig. 12. Extended longitudinal variation of $\sigma_{\text {tsc }}$ during BL4 and BL6 (eastwards from CHN and westwards from PBR) over central $\mathrm{BoB}$ at 770 (upper panel) and $1550 \mathrm{~m}$ (lower panel) altitude. Solid line represents best linear fit illustrating eastward increasing trend in $\sigma_{\text {tsc }}$ values at $770 \mathrm{~m}$.

is from east coast/central India while, airmasses encountered at southern BoB are mainly from East Asia and China. This distinctiveness with respect to the potential source regions would explain the large differences in $\sigma_{\text {tsc }}$ between offVSK and off-CHN (BL1 and BL6) measurements as well as the eastward gradient observed in BL4 and BL6 sorties. Extensive observations in the recent years have shown that during winter season (December-January), the central Indian landmass and the Indo-Gangetic plains experience very high aerosol abundances due to the combined effects of local production, advection, confinement by the shallow winter boundary layer, orography of the region with Himalaya to the north and Vindhya-Satpura to the south forming a channel that slopes from west to east and the prevailing synoptic circulation pattern (Girolamo et al., 2004; Niranjan et al., 2006; Ganguly et al., 2006; Nair et al., 2007). Based on extensive shipboard measurements during ICARB-2006, Nair et al. (2009) have reported a 5 to 8 fold decrease in the $\sigma_{\text {tsc }}$ from the north to south of $\mathrm{BoB}$ (from $\sim 200 \mathrm{M} \mathrm{m}^{-1}$ over northern BoB to reach values as low as $\sim 25 \mathrm{M} \mathrm{m}^{-1}$ in the southern BoB) during the pre-monsoon season (March-April). The values observed in the present study at 770 (1550) $\mathrm{m}$ altitudes were respectively, 227 (150) $\mathrm{M} \mathrm{m}^{-1}$ over northern BoB and $\sim 68$ (42) $\mathrm{M} \mathrm{m}^{-1}$ over central BoB are in general conformity to those.

The two sorties, BL4 and BL6 (with a time gap of around a week), each extending $\sim 4^{\circ}$ off into the central BoB (westward from PBR and eastward from $\mathrm{CHN}$ ), facilitated examining the longitudinal variation of $\sigma_{\text {tsc }}$ over an extended range from $80^{\circ} \mathrm{E}$ to $93^{\circ} \mathrm{E}$ (though with a $4^{\circ}$ gap in between, over the mid BoB). The results, in Fig. 12, show a clear increase with longitude from $\mathrm{CHN}$ to $\mathrm{PBR}$, with a gradient of $\sim 3 \mathrm{M} \mathrm{m}^{-1}$ per degree longitude, and a correlation
$B L 3+B L 5$

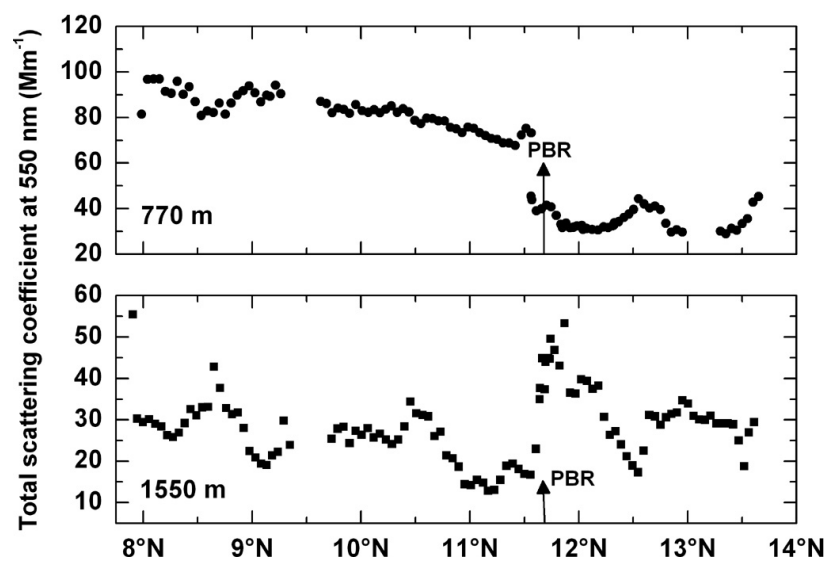

Fig. 13. Latitudinal variation of $\sigma_{\text {tsc }}$ values due north and south of PBR at 770 (upper panel) and $1550 \mathrm{~m}$ (lower panel) altitudes during the sorties BL3 and BL5. The arrows in both the panels represent the latitude of PBR.

coefficient of 0.87 , within the MABL $(770 \mathrm{~m})$. Above the MABL, at $1550 \mathrm{~m}$ altitude, the gradient was quite weak. The above results very clearly indicate that the large heterogeneity in aerosol properties over the BoB during winter is mainly caused by the distinct source impacts; the high values over northern BoB being prominently influenced by the outflow from central India and Indo-Gangetic plains while over the mid eastern BoB, the advection is mainly from the east Asia.

\subsection{Latitudinal variations over eastern BoB}

Two bi-level sorties (BL3 and BL5) were carried out across the latitudes (North-South transect) from the PBR base, making a north-south survey over the island chain. These data are clubbed to examine latitudinal variation of $\sigma_{\text {tsc }}$ over the range from $8^{\circ} \mathrm{N}$ to $14^{\circ} \mathrm{N}$, over PBR (eastern $\mathrm{BoB}$ ). The results are shown in Fig. 13. At both the levels, there exists a north-south gradient, with $\sigma_{\text {tsc }}$, interestingly, decreasing from south to north. While over and north of PBR, the values do not show any significant vertical distribution, being nearly the same $\left(\sim 33 \pm 6 \mathrm{M} \mathrm{m}^{-1}\right)$ at 770 and $1550 \mathrm{~m}$ levels; due south of PBR, there was a significant vertical gradient, with the values at $1550 \mathrm{~m}$ level $\left(\sim 27 \pm 8 \mathrm{M} \mathrm{m}^{-1}\right)$ being less than one-third of the values $\left(\sim 82 \pm 7 \mathrm{Mm}^{-1}\right)$ at $770 \mathrm{~m}$. This is also opposite to the pattern seen close to Indian mainland where there was a large increase in $\sigma_{\text {tsc }}$ northwards with the values off-VSK being much higher that that off-CHN. Going by the geographical features of the Andaman and Nicobar chain of islands, Port Blair (PBR) is its capital, with a major commercial harbor, an airport and a population of $\sim 130000$ (Moorthy et al., 2003). The islands due north of PBR are also fairly habitated compared to those due south of PBR, which are characterized by dense tropical forests and tiny fragmented islands of the Nicobar chain, with highly reduced 
BL3+BL5

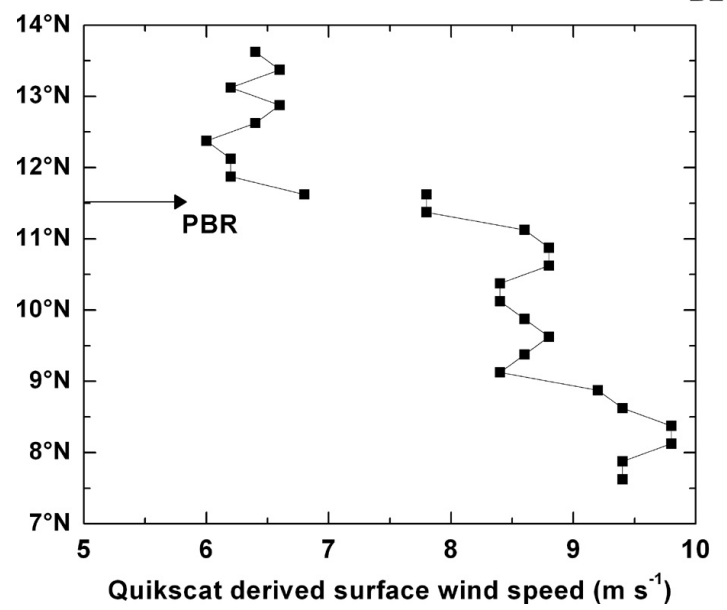

Fig. 14. Latitude profile of surface wind speeds as derived from Quikscat satellite data on the sortie days of BL3 and BL5. The arrow in the figure indicates the latitude of PBR.

habitats. Despite these, the large values of $\sigma_{\text {tsc }}$ due south, and the increasing trend southwards and large vertical gradients suggest the role of abundance of sea-salt aerosols produced in-situ over the southern part of BoB. With a view to examining this, we analyzed surface wind speeds for the sortie days derived from the Quikscat satellite data (Ebuchi et al., 2002), at a spatial resolution of $25 \mathrm{~km} \times 25 \mathrm{~km}$. The latitudinal variation of the mean wind speed is shown in Fig. 14, which depicts a sharp north-south gradient with very high values (as much as $9 \mathrm{~m} \mathrm{~s}^{-1}$ ) in the southern $\mathrm{BoB}$, while due north of PBR, the winds were low to moderate $\leq 6 \mathrm{~m} \mathrm{~s}^{-1}$. This was also confirmed by shipboard observers, who experienced a highly turbulent oceanic environment in the southern BoB. Marine aerosol abundance, primarily the sea-salt component, is known to be strongly influenced by the overocean winds, and is known to increase exponentially with wind speed (e.g. Lovett, 1978; Exton et al., 1985; Hoppel et al., 1990; Moorthy et al., 1997). It has also been well established that such wind generated sea-spray aerosols are mainly in the coarse mode regime, as the generation mechanism (jet droplet production) is most efficient in the size range 0.5 to $3 \mu \mathrm{m}$ (e.g., Blanchard and Woodcock, 1980; Exton et al., 1985; Hoppel et al., 1990; Nair et al., 2008b). Moreover, when wind speed exceeds $\sim 7 \mathrm{~m} \mathrm{~s}^{-1}$, droplets are also produced associated with spume production (Andreas et al., 1995). All these mechanisms would be contributing within the MABL over the southern latitudes off-PBR during our measurements. As the sea-salt aerosols are good scatterers (Single Scattering Albedo (SSA) 1) they contribute significantly to $\sigma_{\mathrm{tsc}}$. This wind generated particles being heavier, would be mostly confined within the MABL (where the species are well mixed) and would have short residence time in the atmosphere. This explains the sharp vertical gradient seen in the southern latitudes.

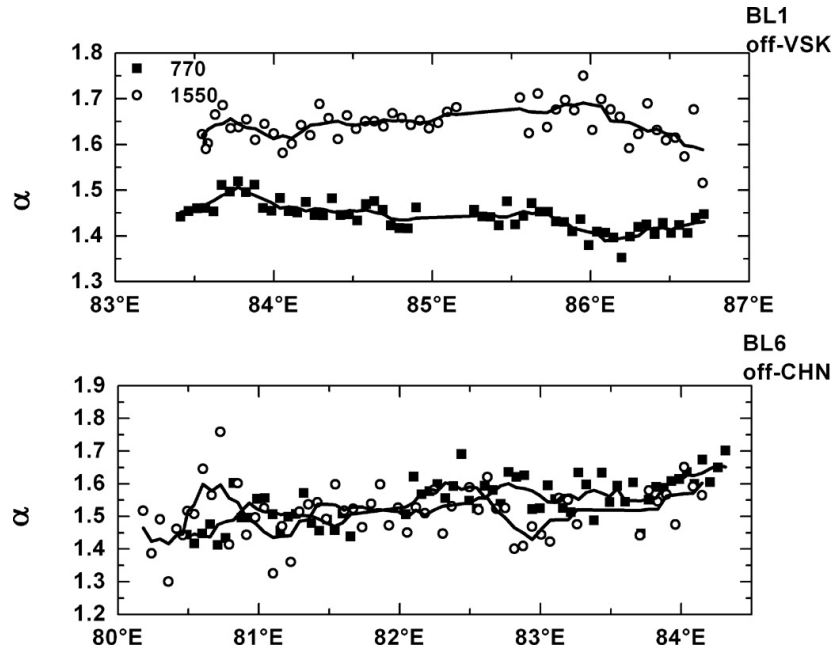

Fig. 15. Longitudinal variation of wavelength exponent $(\alpha)$ offVSK (BL1, top panel) and off-CHN (BL6, bottom panel) at $770 \mathrm{~m}$ and $1550 \mathrm{~m}$ altitudes. Solid line and dashed lines indicates 5 point running mean at $770 \mathrm{~m}$ and $1550 \mathrm{~m}$ altitudes, respectively.

\subsection{Wavelength exponent and hemispheric backscatter ratio}

The wavelength exponent $\alpha$ of $\sigma_{\text {tsc }}$ has been estimated from each measurement of the spectral $\sigma_{\mathrm{tsc}}$, by regression fit to the Angstrom relation. The columnar mean values of $\alpha$ were $1.25 \pm 0.42$ and $1.45 \pm 0.17$ during ML1 and ML2, respectively off-VSK and off-PBR suggesting accumulation mode dominance in the size distribution, particularly over PBR. Notwithstanding this, our values are lower than those reported by Sheridan et al. (2002) over several locations viz., Northern Indian Ocean (2.02), the Southern Great Plains (2.49), Bondville (2.37), Sable Island (2.29) and Barrow (1.71). During the ICARB-2006, Ramachandran and Rajesh (2008) have reported higher values $(\sim 1.84)$ for columnar mean $\alpha$ over Bhubaneshwar; 1.98 (over Chennai); 1.77 (over Trivandrum) and 1.82 (over Goa) for the pre-monsoon season.

The longitudinal variation of $\alpha$ within and above the MABL off-VSK and off-CHN was examined in Fig. 15. OffVSK (BL1), while $\alpha$ remained nearly steady with longitude within the MABL, a weak increasing trend was noticed at the higher level. Significant vertical structure also was seen in the $\alpha$ values, with a mean value of $\sim 1.44 \pm 0.03$ within the MABL and $1.62 \pm 0.04$ above at $1550 \mathrm{~m}$, suggesting smaller particles to dominate at higher levels. Similar increasing trends (with longitude) of $\alpha$ were seen off-CHN also.

The hemispheric backscatter ratio (b) (defined by Eq. 2) is an important parameter in deciding the top of the atmosphere forcing for a given optical depth (Haywood and Shine, 1995). It could also provide the information on the relative continental influence (which tends to raise $\mathrm{b}$ and lower the single scattering albedo) over oceanic environment (Anderson et al., 
Table 3. Mean values of wavelength exponent $(\alpha)$ and aerosol backscatter ratio $(b)$ for all BL and ML sorties within and above MABL. * indicates columnar mean values.

\begin{tabular}{cccccc}
\hline \multirow{2}{*}{ Sortie name } & \multicolumn{2}{c}{$\alpha$} & & \multicolumn{2}{c}{$b(550 \mathrm{~nm})$} \\
\cline { 2 - 3 } \cline { 5 - 6 } & $\sim 770 \mathrm{~m}$ & $\sim 1550 \mathrm{~m}$ & & $\sim 770 \mathrm{~m}$ & $\sim 1550 \mathrm{~m}$ \\
\hline BL1 & $1.44 \pm 0.03$ & $1.62 \pm 0.04$ & & $0.08 \pm 0.002$ & $0.10 \pm 0.003$ \\
BL2 & $1.73 \pm 0.17$ & $1.76 \pm 0.33$ & & $0.14 \pm 0.007$ & $0.14 \pm 0.019$ \\
BL3 & $1.77 \pm 0.09$ & $1.8 \pm 0.13$ & & $0.13 \pm 0.005$ & $0.14 \pm 0.007$ \\
BL4 & $1.53 \pm 0.09$ & $1.6 \pm 0.06$ & & $0.09 \pm 0.004$ & $0.10 \pm 0.004$ \\
BL5 & $1.6 \pm 0.04$ & $1.56 \pm 0.1$ & & $0.09 \pm 0.002$ & $0.10 \pm 0.005$ \\
BL6 & $1.55 \pm 0.06$ & $1.5 \pm 0.08$ & & $0.10 \pm 0.003$ & $0.10 \pm 0.005$ \\
ML1 & $1.25 \pm 0.42^{*}$ & & $0.12 \pm 0.05^{*}$ \\
ML2 & $1.45 \pm 0.17^{*}$ & & \multicolumn{2}{c}{$0.11 \pm 0.04^{*}$} \\
\hline
\end{tabular}

1999). Also, following the Mie theory for spherical aerosols, $b$ will be less than 0.1 for coarse mode aerosols (particle's diameters $>1.5 \mu \mathrm{m})$, implying higher b-values $(>0.1)$ correspond to accumulation mode particle dominance (Wu et al., 2004). Longitudinal and latitudinal variations of $b(550 \mathrm{~nm})$ for all the bi-level sorties were shown in Fig. 16. During BL1 off-VSK, $b$ showed significant vertical structure, being higher above MABL, as seen in the top panel. This was not observed for the other bi-level sorties. During BL6 (off-CHN) and BL4 (off-PBR) $b$ showed comparable values and similar trends, both within and above the MABL with an gradual increasing trend eastward which might be indicative of an increasing continental influence (towards east); aerosols being carried by the synoptic easterly airmass which traverses over the east Asian region (Figs. 9 and 11). The north-south gradient in the $\sigma_{\text {tsc }}$ values, which was observed over PBR, existed even in b within and above MABL; with higher $\sigma_{\text {tsc }}$ values due south of PBR are associated with lower $\mathrm{b}$ values and vice versa. This is an indicative of relative abundance of natural and coarse mode aerosols (sea-spray aerosols produced in-situ due to the action of high wind over the sea surface) due south of PBR, which was also in line with the discussion made in the previous section. The mean values of $\alpha$ and $b$ with standard deviations for all the bi-level and multi-level sorties are given in the Table 3 .

Following the above discussion, similar spatial trends in $\alpha$ and $b$ is expected, as both of these parameters are sensitive to the abundance of accumulation mode aerosols (or the accumulation fraction to the total aerosol). This is examined in Fig. 17, which is a scatter plot of $b$ against the corresponding values of $\alpha$, combining the entire measurements. The regression line through the points indicates the average relation between the two, which is strongly positive with a correlation coefficient of 0.8 .

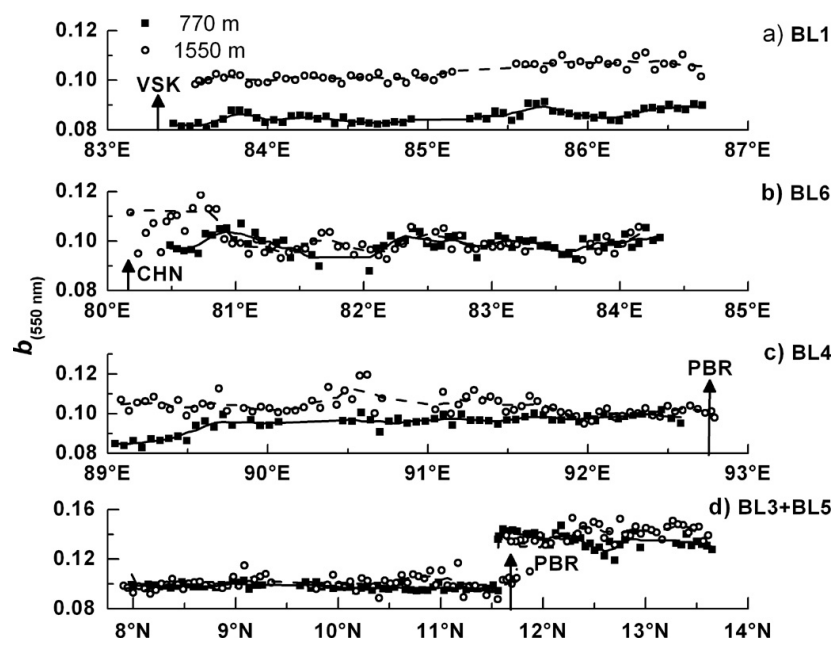

Fig. 16. Longitudinal/latitudinal variation of hemispheric back scatter ratio $(b)$ during bi-level sorties (a) off-VSK (BL1, first panel), (b) off-CHN (BL6, second panel), (c) off-PBR (westwards, BL4, third panel), (d) off-PBR (north-south, BL3+BL5, fourth panel). Solid line and dashed lines indicates 5 point running mean at $770 \mathrm{~m}$ and $1550 \mathrm{~m}$ altitudes, respectively. The arrows indicate the corresponding base stations' longitude/latitude.

\section{Summary}

Airborne measurements of the optical properties of aerosols were carried out over different regions of $\mathrm{BoB}$ during the winter season of 2008-2009 as part of W_ICARB and the investigations revealed that

1. Over western BoB, adjacent to east coast of India, the total scattering coefficients within and above MABL were significantly higher at the northern regions than the central parts by a factor of 3 to 4 . The altitude profile showed a nearly steady value indicating a spatially homogenous state up to $\sim 1.5 \mathrm{~km}$ above ground, after which the scattering coefficient dropped off rapidly. 


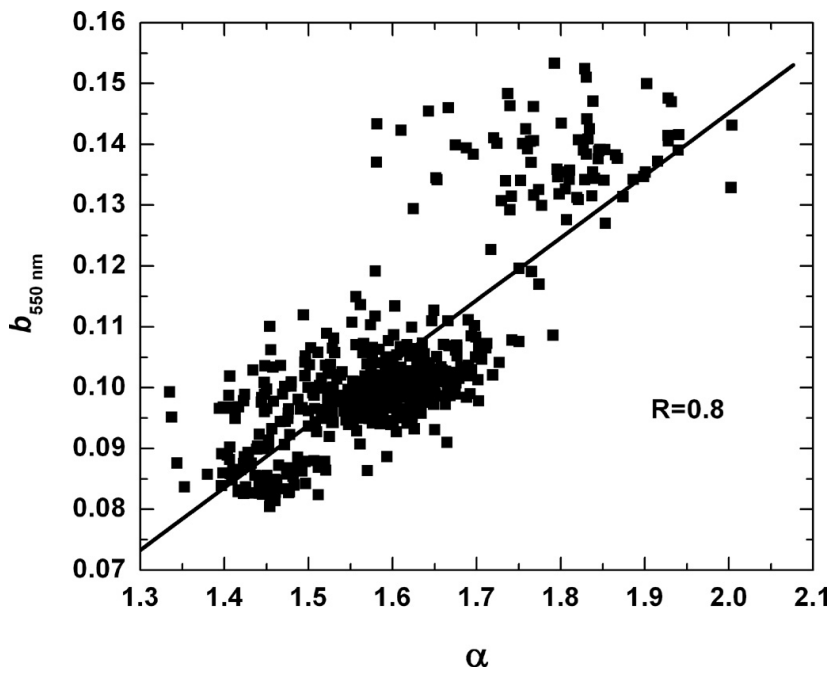

Fig. 17. Scatter plot of hemispheric backscatter ratio $(b)$ against wavelength exponent $(\alpha)$. Solid line represents the linear regression fit between the two parameters.

The vertical structure of atmospheric thermodynamics showed that the region of nearly zero vertical gradient in $\sigma_{\text {tsc }}$ coincide with the atmospheric boundary layer (convectively well-mixed region) as revealed by a nearly altitude invariant value for potential temperature and convectively stable region.

2. In contrast to the above, over eastern $\mathrm{BoB}$, the measurements over the island location, Port Blair (PBR) showed that $\sigma_{\text {tsc }}$ remained steady with altitude up to $\sim 1 \mathrm{~km}$ in the convectively well mixed region and then dropped off gradually with altitude, with a shallower vertical gradient than that seen over east coast of India.

3. The scattering AOD in the region 0-3000 $\mathrm{m}$ altitude was $\sim 0.22$ and 0.14 which accounted for nearly $45 \%$ and $60 \%$ to the columnar AOD off the coastal base Visakhapatnam (VSK, north-western $\mathrm{BoB}$ ) and off the island base PBR (eastern BoB) respectively, suggesting most of the aerosol was confined to lower troposphere, particularly over PBR, during winter, in contrast to that of pre-monsoon season.

4. Over the eastern BoB, due north and south of PBR, within and above MABL, a significant gradient in $\sigma_{\text {tsc }}$ has been observed, with $\sigma_{\text {tsc }}$ decreasing from south to north and also associated with large vertical gradient due south of PBR. This suggested the role of sea-salt aerosol abundance due south of PBR, produced in-situ over the southern part of $\mathrm{BoB}$, due to the action of surface winds. This was also supported by the high surface wind speeds due south of PBR.

5. Over central $\mathrm{BoB}$, eastward gradients in $\sigma_{\mathrm{tsc}}, \alpha$ and $b$, within and above MABL, suggested increasing abun- dance in aerosols with increasing dominance of accumulation mode towards east and increasing continental influence in the aerosol abundance towards east; aerosols being carried over the study region by the synoptic easterly airmass originating from the east Asian regions.

Acknowledgements. The work was carried out under the Geosphere-Biosphere Program of Indian Space Research Organisation. The authors wish to thank the crew of the aircraft for their help throughout the field campaign and the support of the NRSC aircraft team headed by Raghu Venkataraman. The authors profusely acknowledge the Boundary layer physics and Atmospheric modelling group of Space Physics Laboratory for providing the shipboard profiles of meteorological data over Port Blair.

Topical Editor P. Drobinski thanks two anonymous referees for their help in evaluating this paper.

\section{References}

Alappattu, D. P., Subrahamanyam, D. B., Kunhikrishnan, P. K., Somayaji, K. M., Bhat, G. S., Venkatesan, R., Dutt, C. B. S., Singh, A. B., Soni, V. K., and Tripathi, A. S.: On the marine atmospheric boundary layer characteristics over Bay of Bengal and Arabian Sea during the Integrated Campaign for Aerosols, gases and Radiation Budget (ICARB), J. Earth Syst. Sci., 117(S1), 281-291, 2008.

Anderson, T. L. and Ogren, J. A.: Determining aerosol radiative properties using the TSI 3563 integrating nephelometer, Aerosol Sci. Technol., 29, 57-69, 1998.

Anderson, T. L., Covert, D. S., Marshall, S. F., Laucks, M. L., Charlson, R. J., Waggoner, A. P., Ogren, J. A., Caldow, R., Holm, R., Quant, F., Sem, G., Wiedensohler, A., Ahlquist, N. A., and Bates, T. S.: Performance characteristics of a high-sensitivity, three-wavelength, total scatter/backscatter Nephelometer, J. Atmos. Oceanic Technol., 13, 967-986, 1996.

Anderson, T. L., Covert, D. S., Wheeler, J. D., Harris, J. M., Perry, K. D., Trost, B. E., Jaffe, D. J., and Ogren, J. A.: Aerosol backscatter fraction and single scattering albedo: measured values and uncertainties at a coastal station in the Pacific Northwest, J. Geophys. Res., 104(D21), 26793-26807, 1999.

Andreas, E. L., Edson, J. B., Monahan, E. C., Rouault, M. P., and Smith, S. D.: The sea spray contribution to net evaporation from the sea: A review of recent progress, Bound. Lay. Meteorol., 72, 3-52, 1995.

Ångström, A.: The parameters of atmospheric turbidity, Tellus, 16, 64-75, 1964.

Babu, S. S., Satheesh, S. K., Moorthy, K. K., Dutt, C. B. S., Nair, V. S., Alappattu, D. P., and Kunhikrishnan, P. K.: Aircraft measurements of aerosol black carbon from a coastal location in the north-east part of peninsular India during ICARB, J. Earth Syst. Sci., 117(S1), 263-272, 2008.

Bigg, E. K., Gras, J. L., and Mossop, D. J. C.: Wind-produced submicron particles in the marine atmosphere, Atmos. Res., 36, 55-68, 1995.

Blanchard, D. C. and Woodcock, A. H.: The production, concentration and vertical distribution of the sea-salt aerosols, Ann. N. Y. Acad. Sci., 338, 330-347, 1980. 
Chin, M., Ginoux, P., Kinne, S., Torres, O., Holben, B., Duncan, B. N., Martin, R. V., Logan, J. A., Higurashi, A., and Nakajima, T.: Tropospheric aerosol optical thickness from the GOCART model and comparisons with satellite and sunphotometer measurements, J. Atmos. Sci., 59, 461-483, 2002.

Draxler, R. R. and Rolph, G. D.: HYSPLIT (Hybrid Single Particle Lagrangian Integrated Trajectory) model access, available online at http://ready.arl.noaa.gov/HYSPLIT_traj.php, 2003.

Ebuchi. N., Graber, H. C., and Caruso, M. J.: Evaluation of wind vectors observed by QuikSCAT/SeaWinds using ocean buoy data, J. Ocean. Atmos. Tech., 19, 2049-2062, 2002.

Exton, H. J., Latham, J., Park, P. M., Perry, S. J., Smith, M. H., and Allan, R. R.: The production and dispersal of marine aerosol, Q. J. Roy. Meteorol. Soc., 111, 817-837, 1985.

Ganguly, D., Jayaraman, A., Rajesh, T. A., and Gadhavi, H.: Wintertime aerosol properties during foggy and nonfoggy days over urban center Delhi and their implications for shortwave radiative forcing, J. Geophys. Res., 111, D15217, doi:10.1029/2005JD007029, 2006.

Girolamo, L., Bond, T. C., Bramer, D., Diner, D. J., Fettinger, F., Kahn, R. A., Martonchik, J. V., Ramana, M. V., Ramanathan, V., and Rasch, R. J.: Analysis of multiangle imaging spectroradiometer (MISR) aerosol optical depths over greater India during winter 2001-2004, Geophys. Res. Lett., 31, L23115, doi:10.1029/2004GL021273, 2004.

Hanel, G.: The properties of atmospheric aerosol particles as a function of relative humidity ast thermodyanic equilibrium with the surrounding moist air, Adv. Geophys., 19, 73-188, 1976.

Haywood, J. M. and Boucher, O.: Estimates of the direct and indirect radiative forcing due to tropospheric aerosols: a review, Rev. Geophys., 38(4), 513-543, 2000.

Haywood, J. M. and Shine, K. P.: The effect of anthropogenic sulfate and soot aerosol on the clear sky planetary radiation budget, Geophys. Res. Lett., 22, 603-606, 1995.

Hoppel, W. A., Fitzgerald, J. W., Frick, G. M., and Larson, R. E.: Aerosol size distribution and optical properties found in the marine boundary layer over the Atlantic ocean, J. Geophys. Res., 95, 3659-3686, 1990.

Lovett, R. F.: Quantitative measurement of airborne sea-salt in the North Atlantic, Tellus, 30, 358-364, 1978.

Moorthy, K. K. and Babu, S. S.: Aerosol black carbon over Bay of Bengal observed from an island location, Port Blair: Temporal features and long-range transport, J. Geophys. Res., 111, D17205, doi:10.1029/2005JD006855, 2006.

Moorthy, K. K. and Satheesh, S. K.: Characteristics of aerosols over a remote island, Minicoy in the Arabian Sea: Optical properties and retrieved size characteristics, Q. J. Roy. Meteorol. Soc., 126, 81-109, 2000.

Moorthy, K. K., Satheesh, S. K., and Krishna Murthy, B. V.: Investigations of the marine aerosols over tropical Indian Ocean, J. Geophys. Res., 102, 18827-18842, 1997.

Moorthy, K. K., Babu, S. S., and Satheesh, S. K.: Aerosol spectral optical depths over the Bay of Bengal: Role of transport, Geophys. Res. Lett., 30(5), 1249, doi:10.1029/2002GL016520, 2003

Moorthy, K. K., Babu, S. S., Sunilkumar, S. V., Gupta, P. K., and Gera, B. S.: Altitude profiles of aerosol BC, derived from aircraft measurementsover an inland urban location in India, Geophys. Res. Lett., 31, L22103, doi:10.1029/2004GL021336, 2004.
Moorthy, K. K., Satheesh, S. K., Babu, S. S., Dutt, C. B. S.: Integrated Campaign for Aerosols, gases and Radiation Budget (ICARB): An Overview, J. Earth System Sci., 117(S1), 243-262, 2008.

Moorthy, K. K., Beegum, S. N., Babu, S. S., Smirnov, A., John, S. R., Kumar, K. R., Narasimhulu, K., Dutt, C. B. S., and Nair, V. S.: Optical and physical characteristics of Bay of Bengal aerosols during W]ICARB: Spatial and vertical heterogeneities in the marine atmospheric boundary layer and in the vertical column, J. Geophys. Res., 115, D24213, doi:10.1029/2010JD014094, 2010.

Nair, V. S., Moorthy, K. K., Alappattu, D. P., Kunhikrishnan, P. K., George, S., Nair, P. R., Babu, S. S., Abish, B., Satheesh, S. K., Tripathi, S. N., Niranjan, K., Madhavan, B. L., Sreekanth, V., Dutt, C. B. S., Badarinath, K. V. S., and Reddy, R. R.: Wintertime aerosol characteristics over the Indo-Gangetic Plain (IGP): Impacts of local boundary layer processes and long-range transport, J. Geophys. Res., 112, D13205, doi:10.1029/2006JD008099, 2007.

Nair, V. S., Babu, S. S., and Moorthy, K. K.: Spatial distribution and spectral characteristics of aerosol single scattering albedo over the Bay of Bengal inferred from shipborne measurements, Geophys. Res. Lett., 35, L10806, doi:10.1029/2008GL033687, 2008a.

Nair, Vijayakumar S., Suresh Babu, S., Satheesh, S. K., and Krishna Moorthy, K.: Effects of sea surface winds on marine aerosols characteristics and impacts on longwave radiative forcing over the Arabian Sea, Atmos. Chem. Phys. Discuss., 8, 15855-15899, doi:10.5194/acpd-8-15855-2008, 2008b.

Nair, V. S., Babu, S. S., Moorthy, K. K., and Satheesh, S. K.: Optical and physical properties of atmospheric aerosols over the Bay of Bengal during ICARB, J. Atmos. Sci., 66(9), 2640-2658, doi:10.1175/2009JAS3032.1, 2009.

Niranjan, K., Sreekanth, V., Madhavan, B. L., and Moorthy, K. K.: Wintertime aerosol characteristics at a north Indian site Kharagpur in the Indo-Gangetic plains located at the outflow region into Bay of Bengal, J. Geophys. Res., 111, D24209, doi:10.1029/2006JD007635, 2006.

Ramachandran, S. and Rajesh, T. A.: Asymmetry parameters in the lower troposphere derived from aircraft measurements of aerosol scattering coefficients over tropical India, J. Geophys. Res., 113, D16212, doi:10.1029/2008JD009795, 2008.

Sakerin, S. M. and Kabanov, D. M.: Spatial inhomogeneties and the spectral behavior of atmospheric aerosol optical depth over the Atlantic Ocean, J. Atmos. Sci., 59(3), 484-500, 2002.

Satheesh, S. K., Srinivasan, J., and Moorthy, K. K.: Spatial and temporal heterogeneity in aerosol properties and radiative forcing over Bay of Bengal: Sources and role of aerosol transport, J. Geophys. Res., 111, D08202, doi:10.1029/2005JD006374, 2006.

Satheesh, S. K., Moorthy, K. K., Babu, S. S., Vinoj, V., and Dutt, C. B. S.: Climate implications of large warming by elevated aerosol over India, Geophys. Res. Lett., 35, L19809, doi:10.1029/2008GL034944, 2008.

Satheesh, S. K., Moorthy, K. K., Babu, S. S., Vinoj, V., Nair, V. S., Beegum, S. N., Dutt, C. B. S., Alappattu, D. P., and Kunhikrishnan, P. K.: Vertical structure and horizontal gradients of aerosol extinction coefficients over coastal India inferred from airborne lidar measurements during the Integrated Campaign for Aerosol, Gases and Radiation Budget (ICARB) field campaign, J. Geophys. Res., 114, D05204, doi:10.1029/2008JD011033, 2009. 
Sheridan, P. J., Jefferson, A., and Ogren, J. A.: Spatial variability of submicrometer aerosol radiative properties over the Indian Ocean during INDOEX, J. Geophys. Res., 107(D19), 8011, doi:10.1029/2000JD000166, 2002.

Smirnov, A., Holben, B. N., Kaufman, Y. J., Dubovik, O., Eck, T. F., Slutsker, I., Pietras, C., and Halthore, R. N.: Optical properties of atmospheric aerosol in maritime environments, J. Atmos. Sci., 59, 501-523, 2002.

Smirnov, A., Holben, B. N., Eck, T. F., Dubovik, O., and Slutsker, I.: Effect of wind speed on columnar aerosol optical properties at Midway Island, J. Geophys. Res., 108(D24), 4802, doi:10.1029/2003JD003879, 2003.
Stull, R. B.: An Introduction to Boundary Layer Meteorology, Springer, New York, 1988.

Twomey, S.: The influence of pollution on the shortwave albedo of clouds, J. Atmos. Sci., 34, 1149-1152, 1977.

Von Glasow, R., Sander, R., Bott, A., and Crutzen, P. J.: Modelling halogen chemistry in the marine boundary layer -2 . Interactions with sulfur and the cloud-covered MBL, J. Geophys. Res., D17, 4323, doi:10.1029/2001JD000942, 2002.

Wu Zhang, Bo Hu, Changhe Chen, Ping Du, Lei Zhang, and Guanghong Feng.: Scattering properties of atmospheric aerosols over Lanzhou city and applications using an integrating nephelometer, Adv. Atmos. Sci., 21, 848-856, 2004. 